\title{
A história ensinada: algumas configurações do saber escolar
}

Ana Maria F.C. Monteiro"

\section{RESUM0}

0 ensino de História tem sido objeto de grande interesse, constituindo um campo de pesquisas em desenvolvimento no Brasil. Nesse sentido, os autores que utilizam os conceitos "saber escolar" (Forquin,Develay,Lopes), "disciplina escolar" (Chervel, Goodson), "transposição didática" (Chevallard, Develay, Moniot) e "mediação didática" (Lopes), oferecem perspectivas promissoras para a compreensão de processos característicos da cultura escolar, cuja especificidade passa à ser reconhecida e considerada. Autilização exclusiva do instrumental teórico da pesquisa historiográfica para a análise de saberes e práticas constituintes de uma cultura com lógicas e dinâmicas próprias, produziu alguns equívocos com a identificação de erros onde, muitas vezes, havia diferenças. Este artigo tem por objetivo discutir algumas construções próprias do saber escolar, identificadas e analisadas na dimensão do chamado currículo em ação, ou seja, da história ensinada, onde o instrumental teórico da historiografia se articula com aquele oriundo do campo da pesquisa educacional para abordar construções elaboradas para 0 ensino escolar, nas quais a instrução está imbricada com a finalidade educativa.

Palavras-chave: ensino de História, saber histórico escolar, história ensinada, mediação didática, construções conceituais, currículo em ação.

Estudos e pesquisas voltados para as questões relativas ao currículo têm se desenvolvido de forma significativa a partir das contribuições de autores que, ao abordar as relações entre escola e cultura, possibilitaram a melhor compreensão do papel desempenhado pela escola na produção da memória coletiva, das identidades sociais e da reprodução (ou transformação) das relações de poder.

A sociologia do currículo abriu, portanto, novas perspectivas para a

* Professora de Didática e Prática de Ensino de História da Faculdade de Educação da Universidade Federal do Rio de Janeiro. E-mail: anamont@ufrj.br 
abordagem dos saberes ensinados que, ao longo da maior parte do século XX, não foram objeto de questionamentos ou reflexão: eram os saberes definidos e organizados nos programas e currículos como aqueles a ensinar, oriundos de uma base científico-cultural ampla, através de meios e procedimentos acertados, escolhidos num "receituário ou arsenal" construído e fundamentado cientificamente nos conhecimentos oferecidos pela psicologia, psicopedagogia e didática.

Essa perspectiva racionalista, que contém uma crítica ao modelo empirista e espontaneísta, ao defender uma aplicação dos conhecimentos e métodos científicos para a melhor realização da prática docente é, por sua vez, objeto de críticas, atualmente, que apontam a simplificação inerente à concepção que a fundamenta.

Por um lado, as pesquisas confirmam que o currículo é um campo de criação simbólica e cultural, permeado por conflitos e contradições, de constituição complexa e híbrida, com diferentes instâncias de realização: currículo formal, currículo real ou em ação, currículo oculto (MOREIRA, 1997, 13, 14). Por outro lado, discussões e reflexões no campo da epistemologia têm sido realizadas considerando a relatividade do conhecimento científico, ou seja, descartando a visão de que a ciência produz a única forma de conhecimento válido e verdadeiro, reconhecendo a diversidade de formas de conhecimento com diferentes racionalidades e formas de validação (MOREIRA, 1997, 23).

Além disso, " a realidade social não se deixa encaixar em esquemas preestabelecidos do tipo taxonômico ou processual. A tecnologia educativa não pode continuar a lutar contra as características, cada vez mais evidentes, dos fenômenos práticos: complexidade, incerteza, instabilidade, singularidade e conflito de valores" (GÓMEZ, 1995, 99). Professores e alunos são sujeitos, portadores de visões de mundo e interesses diferenciados, que estabelecem relações entre si com múltiplas possibilidades de apropriação e interpretação.

Essas novas perspectivas, que reconhecem a complexidade das questões envolvidas no ato de ensinar, permitem avançar em relação a estudos e análises que, não reconhecendo a especificidade da cultura escolar, buscavam o avanço apenas através da maior aproximação com o conhecimento científico. 0 ensino seria melhor na medida em que mais semelhante, coerente e atualizado fosse em relação 'a produção científica contemporânea.

Essa orientação induzia pesquisadores a identificar "erros" recorrentes 
no ensino realizado nas escolas na medida em que a sua atualização se faz mais lentamente, e também porque um processo de síncrese é realizado, com a utilização de contribuições de vários autores, muitos deles operando com pressupostos teóricos distintos, para configurar explicações ou exemplificações. ${ }^{1}$

Ao ser radicalizada, essa concepção levou muitos a considerar o saber escolar um saber de "segunda", inferior ao conhecimento científico, porque resultante de simplificações necessárias para o ensino a crianças, adolescentes ou adultos ignorantes, o que contribuiu para acirrar preconceitos em relação . à educação escolar, com consequências perversas para o desenvovimentos das práticas educacionais. Não estou defendendo aqui que todo ensino escolar é bem desenvolvido e imune a erros ou contradições. Minha crítica, apoiada nos autores já citados, volta-se para uma visão simplificadora que ignora a especificidade da cultura e do saber escolar, impedindo avanços para sua melhor realização. Para isso, as contribuições do conhecimento científico que está em constante processo de crítica e renovação são fundamentais. Mas precisamos compreender melhor como se dá a produção do saber escolar, que envolve a interlocução com o conhecimento científico, mas também com outros saberes presentes e que circulam no contexto socio-cultural de referência.

Contribuindo para tornar ainda mais complexa essa construção, não podemos esquecer que a produção do saber escolar é permeada pela dimensão educativa que desempenha papel estruturante em sua configuraçã $\emptyset$, contribuindo de forma significativa para sua especificidade epistemológica, além de ser instrumento fundamental para a crítica, superação e reconstituição do senso comum (MOREIRA, 1997, 22-26).

Com base nesses pressupostos, este artigo tem por objetivo discutir algumas construções próprias do saber escolar, identificadas e analisadas na dimensão do chamado currículo em ação. Como objeto de análise, trabalho com a história ensinada, buscando articular o instrumental teórico da historiografia com aquele oriundo do campo da pesquisa educacional para abordar construções elaboradas para o ensino escolar, nas quais a instrução está imbricada com a finalidade educativa.

\footnotetext{
1 Foram muito frequentes pesquisas que buscavam identificar as concepções de História subjacentes aos saberes ensinados e que muitas vezes identificavam a multiplicidade como problema e não como alternativa possivel ou necessária aos objetivos propostos.
} 
Na primeira parte, desenvolvo uma discussão com autores que operam com o conceito de transposição didática para compreender os processos de elaboração do saber escolar. Na segunda parte, faço a análise de algumas configurações da História ensinada utilizando o instrumental conceitual relacionado ao saber escolar conforme discutido anteriormente. ${ }^{2}$

\section{0 saber escolar}

As perspectivas de abordagem das questões educacionais têm sido objeto de importante renovação teórica principalmente aquelas relacionadas à dimensão cognitiva/cultural dos processos educativos, e que são objeto do campo do currículo. Nas análises realizadas em diferentes perspectivas: sociológica, dos estudos culturais, da história das disciplinas escolares ou da didática, considero relevante destacar aquelas desenvolvidas com base no reconhecimento da especificidade e complexidade do campo educacional como objeto de pesquisa. ${ }^{3}$

Esse movimento implicou e expressou uma ressignificação do conceito de cultura que fundamenta a ação educativa. De uma concepção universal, individualista, elitista, prescritiva e normativa passou-se a uma concepção compreensiva, relativista, pluralista, baseada na perspectiva antropológica e sociológica. A escola, mais do que um local de instrução e transmissão de saberes, passou a ser considerada como um espaço configurado e configurador de uma cultura escolar, onde se confrontam diferentes forças e interesses sociais, econômicos, politicos e culturais (FORQUIN, 1993).

No contexto dessas mudanças, os saberes, antes inquestionados, passaram a ser objeto de uma série de indagações que se voltaram, de um lado, para aspectos relacionados aos processos de seleção cultural - quais saberes, motivos de opção, implicações culturais e repercussões sociais e políticas das opções, negações, ocultamentos, ênfases, etc. em estudos realizados em perspectiva sociológica ou sociohistórica (YOUNG,1971; APPLE, 1982; CHERVEL, 1990; GOODSON, 1998).

2 Esse artigo foi elaborado a partir de subsídios obtidos com a pesquisa realizada para Tese de Doutoramento, intitulada"Ensino de História: entre saberes e práticas"realizada no Departamento de Educação da PUC/ RIO e defendida em agosto de 2002, sob a orientação do Professor Francisco Creso Franco.

3 Para um balanço das tendências mais recentes dos estudos e pesquisas no campo do currículo em educação, ver Santos, 1990, Moreira, 1997 e Silva, 1999. Para uma análise da evolução recente das tendências dentro do debate sobre as relações entre escola, cultura e desigualdades sociais na França, em perspectiva sociológica, ver Forquin, 2001. 
Por outro lado, estudos foram realizados para investigar os processos de constituição desses saberes, os percursos realizados nos processos didatização, utilizando uma abordagem orientada por perspectiva epistemológica, buscando superar a visão instrumental e técnica predominante até então. No bojo desses estudos emergiu a formulação do conceito de saber escolar enquanto um saber com configuração cognitiva própria e original da cultura escolar (FORQUIN, 1992, 1993; LOPES, 1997, p. 97-98).

Como afirma Forquin (1992), existem diferenças substanciais entre a exposição teórica e a exposição didática. A primeira deve levar em conta 0 estado do conhecimento, a segunda, o estado de quem conhece, os estados de quem aprende e de quem ensina, sua posição respectiva com relação ao saber e a forma institucionalizada da relação que existe entre um e outro, em tal ou qual contexto social. Não se trata apenas de fazer compreender, mas de fazer aprender, de fazer incorporar ao habitus (FORQUIN, 1992, p. 34).

Assim, a perspectiva de constituição de um saber escolar tem por base a compreensão de que a educação escolar não se limita a fazer uma seleção entre o que há disponível da cultura num dado momento histórico, mas tem por função tornar os saberes selecionados efetivamente transmissíveis e assimiláveis. Para isso, exige-se um trabalho de reorganização, reestruturação ou de transposição didática que dá origem a configurações cognitivas tipicamente escolares, capazes de compor uma cultura escolar sui generis, com marcas que transcendem os limites da escola (FORQUIN, 1993, p. 16-17).

Os estudos voltados para a questão do saber escolar receberam importante contribuição através do uso do conceito de transposição didática enunciado, pela primeira vez, por Verret em sua tese Les Temps des Études, defendida em 1975 na França (FORQUIN, 1993, p. 16). Posteriormente, Chevallard e Joshua (1982) utilizaram este conceito no campo do ensino da matemática para examinar as transformações sofridas pela noção matemática de distância entre 0 momento de sua elaboração por Fréchet, em 1906, e o momento de sua introdução nos programas de geometria franceses, em 1971 (LOPES, 1999, p. 206) ${ }^{4}$

De acordo com Chevallard (1991), seu ponto de partida é o interesse em inscrever a "didática das matemáticas" (p. 14), campo de voluntarismos, como

4 Neste trabalho optei por trabalhar com o conceito de transposição didática que atende melhor 'as exigências das questões da pesquisa. Portanto, embora as considere muito relevantes e férteis, não estou trabalhando com as proposições de Chervel sobre a história das disciplinas escolares.

História \& Ensino, Londrina, v. 9, p. 9-35, out. 2003 
um objeto passível de conhecimento científico. Para isso, ele opera com 0 conceito de "sistema didático" - relação ternária que liga um docente, os alunos e um saber. Esse conceito permite trazer para análise o terceiro termo o saber, geralmente esquecido (ou não considerado por ser dado, naturalizado), para ser objeto de investigação. Qual a sua relação com o docente? Que saber é este? Qual a sua relação com o saber acadêmico? Qual a sua relação com os alunos? 'Todas essas questões tocam em pontos como apropriações, elaborações, filiações, gênesis, legitimidades, que abrem perspectivas de análise inovadoras. ${ }^{5}$

0 autor define o conceito de transposição didática como aquele que remete à " passagem do saber acadêmico ao saber ensinado e, portanto, à distância eventual, obrigatória que os separa, que dá testemunho deste questionamento necessário, ao mesmo tempo em que se converte em sua primeira ferramenta." (p. 16)

Chevallard afirma categoricamente a diferença entre o saber acadêmico (savoir savant) e o saber ensinado (savoir enseigné). Para que o ensino seja possível " o elemento de saber deverá ter sofrido certas deformações (grifo adicionado) que o tornarão apto a ser ensinado. 0 saber-tal-como-é-ensinado, o saber ensinado,é necessariamente distinto (grifo adicionado) do saber-inicialmente-designadocomo-aquele-que-deve-ser-ensinado, o saber a ensinar" ( $p .16,17)$. 0 conceito de transposição didática permite então que o campo científico da didática se constitua pois, além de definir uma ruptura, ele cria um instrumento de inteligibilidade que possibilita a realização das investigações, abrindo caminho para que a caixa-preta em que tem estado inserido o ensino comece a ser desvendada. ${ }^{6}$

5 A emergência desse conceito ocorre no contexto das lutas internas pela afirmação do campo da didática na França, na década de 1980, opondo defensores de uma didática geral e aqueles defensores das didáticas específicas. Nesse sentido, o autor não opera com o conceito de saber escolar (que traz implícita a dimensão cultural) e sim "saber a ensinar "e "saber ensinado".

6 Uma tendência dominante entre as pesquisas educacionais nos anos 60 e 70 do século XX focalizava os processos de aprendizagem numa perspectiva orientada pelas concepções da psicologia e da psicogênese como base para a compreensão e melhor realização dos processos de ensino. Atualmente, pesquisas orientadas pelo entendimento de que o ensino implica em processo com características próprias que precisam ser melhor conhecidas têm sido realizadas. Como afirma Berliner(1980, p. 80) citado por Gauthier(1998, p. 52), "Assim como os princípios da arte culinária não provêm do estudo das maneiras de comer, assim também os princípios do ensino não podem derivar do estudo da aprendizagem." Ou, como afirma Moniot "a didática de uma disciplina não é alguma coisa que vem antes dela, a mais ou ao lado, para lhe dar uma espécie de suplemento pedagógico útil ....A didática se ocupa de racionalizar, de muito perto, o ensino. Ela envolve as operações que se realizam quando se aprende uma disciplina, a serviço dessa aprendizagem, para melhor focalizar e dominar os problemas que se apresentam quando se ensina: em suma, exercer o ofício de ensinar, tanto quanto seja possível com conhecimento de causa."(MONIOT, 1993, p. 5) 
0 autor apresenta os vários saberes que se constituem no processo de transposição didática no sentido mais amplo, sensu lato: saber acadêmico, saber a ensinar, saber ensinado, saber aprendido. Identificar as mudanças, que são de ordem conceitual, abre caminhos para melhor conhecer o processo numa análise que reconheça a pluralidade de saberes e o papel das diferentes subjetividades e interesses envolvidos no processo. Uma conclusão que se pode extrair de sua formulação, além da afirmação de uma pluralidade de saberes constituídos no processo de ensino, é que o saber acadêmico é sempre anterior ao saber ensinado

De acordo com o autor, o saber ensinado é naturalizado, um saber sem história, "como algo que não é de nenhum tempo, nem de nenhum lugar, e não legitimando-se mediante 0 recurso à autoridade de um autor, qualquer que seja"(p. 18). Ele adquire a evidência incontestável das coisas naturais. É um saber que aparece na escola exilado de suas origens. Essa naturalização é possível, para Chevallard, por que o sistema didático é aberto e compatível com o seu contexto, tanto no que se refere ao saber acadêmico como à cultura onde se insere e com a qual a escola se relaciona, o que the proporciona flexibilidade e força como fundador de valores.

Chevallard chama a atenção para o fato de que a transposição didática não é realizada pelos professores por si mesmos. Ela tem início quando técnicos, representantes de associações, professores militantes, que compõem a noosfera, definem, a partir do saber acadêmico e através de um trabalho de seleção e estruturação didática, o saber a ensinar, definição esta que será refeita em outros momentos, quando surgir a necessidade de sua renovação ou atualização. " Um conteúdo de saber que foi designado como 'saber a ensinar' sofre a partir de então, um conjunto de transformações adaptativas que vão torná-lo apto para ocupar um lugar entre os 'objeto de ensino'. Ao trabalho que transforma um objeto de saber a ensinar em um objeto de ensino denominamos transposição didática" (CHEVALLARD, 1991, p. 45). A definição do saber a ensinar apresenta portanto os caminhos possíveis para a elaboração do saber enquanto um objeto de ensino. Os professores trabalham na transposição didática, não fazem a transposição didática. "Quando o professor intervém para escrever a variante local do texto do saber que ele chama seu curso, a transposição didática já começou há muito tempo" (1991, p. 20).

Assim, a transposição didática, lato sensu se inicia com a definição dos 
saberes a ensinar a partir do saber acadêmico, realizada pela noosfera, e a transposição didática interna, stricto sensu, realizada pelos professores, dá continuidade ao processo elaborando algumas das versões possíveis do saber ensinado. A seleção dos saberes a ensinar pela noosfera resulta, por sua vez, de lutas e negociações políticas envolvendo legitimações ou contestações de poderes na sociedade em geral, no campo acadêmico e/ou socio-profissional, ou no contexto educacional mais específico.

Para 0 autor, o contraste com o saber acadêmico é fundamental pois permite que se desvele a ficção da unidade do saber ensinado com o saber acadêmico, possibilitando a articulação da análise epistemológica com a análise didática. É a análise do conceito no saber acadêmico comparada com a análise do mesmo conceito no saber ensinado que pode revelar a especificidade da construção didática realizada.

Contrastar o saber escolar com o saber acadêmico permite identificar as transformações e as características, principalmente na sociedade atual, onde as ciências constituem um corpo sistematizado de conhecimentos, elaborados a partir de critérios rigorosos quanto aos aspectos de ordem teórico-metodológica, e onde o saber escolar vai buscar legitimidade.

Esses processos de explicitação do texto do saber, inerentes à transposição didática, implicam numa descontextualização face 'as problemáticas do campo científico. 0 saber é "desenraizado da rede de problemáticas e problemas que the outorgam seu sentido completo" (CHEVALLARD, 1991, p. 71) Sua recontextualização no campo educacional decorre de constrangimentos próprios à cultura escolar e, segundo Chevallard, gera saberes originais que precisam da interlocução com 0 saber acadêmico, através de análise epistemológica, para poderem ser desvelados.

Considero que a contribuição de Chevallard tem um potencial instigante que, aliado à contribuições de outros autores, pode fornecer um instrumental para a melhor compreensão dos processos de ensino, considerando as especificidades das diferentes disciplinas. 0 principal deles é a identificação das mudanças conceituais efetuadas durante 0 processo de transposição didática a partir das necessidades da "razão didática", ou seja, a lógica que exige que o saber ensinado, além do fato de atender a uma razão sociológica (demandas políticas e culturais), precisa ser possível de ser ensinado.?

7 Observe-se, mais uma vez, que o autor está preocupado com a questão didática e não propriamente com a questão educativa do ponto de vista sociológico e político. 
Para a análise da história ensinada, no entanto, sua contribuição precisa ser complementada e revista de forma que a relação hierarquizada com o saber acadêmico venha a ser relativizada abrindo espaço para a compreensão do papel da dimensão educativa em sua estruturação.

Nesse sentido, Develay (1992) traz para a análise o conceito de prática social de referência, originalmente formulado por Martinand (1986), que se refere "a atividades sociais diversas (atividades de pesquisa, de produção, de engenharia, domésticas e culturais) que podem servir de referência as atividades escolares e a partir das quais se pode examinar, no interior de uma disciplina dada, o objeto de trabalho, ou seja, o domínio empírico que constitui a base de experiência real ou simbólica sobre a qual irá se basear o ensino" (DEVELAY, 1992, p. 22-23) ${ }^{8}$

Para Develay "o saber a ensinar, na maior parte das disciplinas, tem como ascendentes os saberes acadêmicos e as práticas sociais de referência, práticas sociais essas que podem estabelecer ou não relações com os saberes acadêmicos - dos quais elas constituem, muitas vezes uma aplicação" (1993, p. 24). Develay propõe uma representação dos fluxos das referências durante a transposição didática que reproduzimos aqui por considerá-la bastante elucidativa (1993, p. 25):

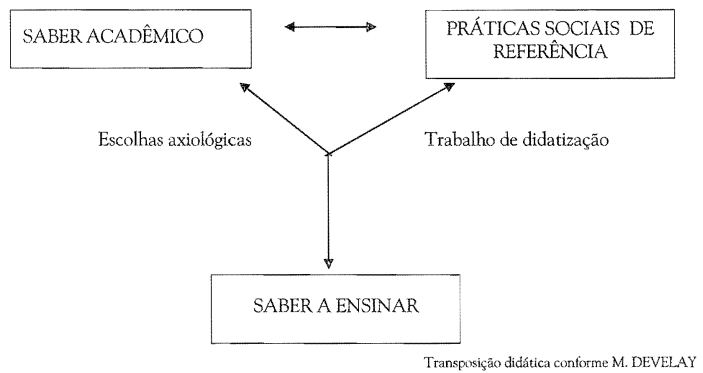

Develay amplia e flexibiliza a operação de transposição ao incluir as

8 Moniot vê em Martinand uma contribuição mais rica e menos preconceituosa que a de Chevallard. Assim, "no lugar da denúncia de uma perversão da referência acadêmica e ao desvelamento de uma ilusão, ele (Martinand) apresenta a criação de um terreno novo onde se pode analisar a transposição incluindo um concorrente positivo à referência acadêmica." (MONI0T, 1993, p. 25) 
práticas sociais de referência e ao considerar, inclusive, que o movimento não é apenas descendente, do saber acadêmico para o saber a ensinar. 0 movimento pode ser ascendente como é o caso, por exemplo, da gramática, criação da escola francesa para o ensino da ortografia, na primeira metade do século XIX, e que só posteriormente passou a ser objețo de saber acadêmico (CHERVEL, 1991). As práticas sociais podem, por sua vez também, influir na formulação de saberes acadêmicos.

Tendo por base essas considerações, acredito que uma alternativa para superar a insuficiência do conceito de transposição didática, inclusive no que diz respeito à sua própria denominação, pode ser a utilização do conceito de mediação didática conforme proposto por Lopes que afirma: "prefiro referir-me a um processo de mediação didática, todavia não no sentido genérico conferido 'a mediação: ação de relacionar duas ou mais coisas, de servir de intermediário ou ponte, de permitir a passagem de uma coisa a outra. Utilizo o termo "mediação" em seu sentido dialético: um processo de constituição de uma realidade através de mediações contraditórias, de relações complexas, não imediatas, com um profundo senso de dialogia" (LOPES, 1997, p. 106).

Além do trabalho de didatização, Develay chama a atenção para 0 fato de que a transposição didática implica num trabalho de axiologização, que expressa os valores escollhidos pelo agentes da transposição, que é mais visível, por exemplo, no ensino da História e da Língua, mas que está presente em todas as disciplinas escolares. Os valores são transmitidos não apenas através dos métodos de ensino (que podem induzir 'a passividade ou a posturas ativas e críticas), mas também através dos conteúdos selecionados para serem ensinados. Eles estão presentes em forma de "filigrana" nos conteúdos escolares e revelam as escolhas éticas de uma sociedade. "Assim, os saberes escolares remetem a valores que, mesmo implícitos, revelam em última análise as escolhas éticas de uma sociedade. Elas merecem ser investigadas porque permitem revelar, a partir dos conteúdos, a filosofia de educação subjacente" (DEVELAY, 1992, p. 26).

Cabe desiacar que o processo de axiologização, inerente ao processo de produção dos saberes escolares, ocorre tanto na transposição didática externa como interna, expressando e possibilitando leituras, apropriações e opções dos diferentes atores - agentes da noosfera, professores e alunos. No caso da História, esse processo de axiologização é inerente também ao processo de produção do 
saber acadêmico, expressando opções e afinidades dos pesquisadores. A axiologização representa a opção feita no que tange à dimensão educativa, podendo expressar-se através da seleção cultural - ênfases - omissões negações, através de aspectos inerentes ao chamado currículo oculto e também as formas como os professores mobilizam os saberes que ensinam.

Esse aspecto, que remete ao entendimento deste autor sobre a autonomia relativa dos professores no momento da transposição didática interna, nos permite destacar outra contribuiuição importante de sua proposta teórica: ela cria instrumentos para se considerar a questão da autoria dos docentes no seu fazer, evitando uma supervalorização romântica de sua atuação.

Didatização e axiologização são, portanto, dois conceitos que articulados, permitem trazer a discussão da transposição didática para 0 campo da teoria educacional crítica e pos-crítica, através da análise epistemológica.

Conforme nos diz Lopes "não podemos nos furtar a discutir o que é fundamental ser ensinado na escola. Não podemos negar o papel preponderante da escola como socializadora de saberes, nem a importância de combatermos tendências relativistas que se negam a admitir alguns saberes como mais fundamentais do que outros, em função do desenvolvimento histórico do conhecimento e em função do modelo de sociedade que desejamos. Mas o papel da epistemologia não se resume à discussão da validade epistemológica dos saberes, mas na possibilidade de introduzir uma nova forma de compreender e questionar o conhecimento, internamente, na sua própria forma de se constituir. Assim a epistemologia contribui diretamente para a definição dos diferentes saberes sociais e de suas relações. Ao questionarmos a razão instrumental, os conhecimentos absolutizados, a unidade e universalidade da razão, não devemos desmerecer a razão, a epistemologia, a relação dialética entre objetividade e subjetividade" (LOPES, 1999, p. 166-167).

\section{A história ensinada}

Com base nas considerações feitas, faço agora, a análise de algumas construções da história ensinada a partir de subsídios obtidos na pesquisa realizada com duas professoras de sexta série do ensino fundamental. 
Seguindo as diretrizes constantes nos PCNs para $03^{\circ}$ ciclo, elas trabalhavam com 0 eixo temático "História das relações sociais, da cultura e do trabalho", dando continuidade ao que fora realizado no ano anterior.

Assim, paralelamente à montagem e orientações para a realização de um trabalho coletivo para a aprendizagem de procedimentos de pesquisa escolar, e da formação e avaliação das atitudes, elas criaram situações para a aprendizagem das relações sociais escravistas, tema que concentrou os esforços durante o segundo bimestre do ano letivo.

Após a revisão de alguns conceitos fundamentais como " trabalho coletivo", "divisão natural do trabalho", "propriedade coletiva", "igualdade social", "excedente", "desigualdade social", trabalhados no ano anterior, elas iniciaram o estudo do tema: " 0 trabalho e as relações sociais: a escravidão", com base no texto do livro didático, referente ao capítulo 16, " 0 trabalho escravo construindo o Brasil". Na primeira parte deste capítulo, o autor resgata algumas informações sobre a escravidão na Antiguidade - as atividades dos escravos, responsáveis pela grandeza daquelas sociedades, como o desaparecimento do Império Romano representou a decadência deste tipo de trabalho; relembra que este tipo de trabalho entrou em decadência na sociedade feudal, e também o restabelecimento da escravidão por portugueses e outros povos europeus durante a colonização da América, a partir do século XVI.

Os subtítulos do capítulo. voltado para o estudo do "Trabalho escravo construindo o Brasil" permitem melhor acompanhar a estrutura da explicação: A volta do trabalho forçado: revisão da escravidão na Antiguidade, a expansão comercial na Europa a partir dos séculos XIII e XIV, os motivos da utilização do trabalho escravo na América, a experiência portuguesa com o uso de escravos africanos nas ilhas do Atlântico e sua introdução no Brasil; As sociedades africanas: o contato dos portugueses com os povos africanos do litoral ocidental da África, características dos reinos e tribos af́ricanos, a escravidão entre os africanos; O escravo como mercadoria: a transformação do escravo em mercadoria, as formas de obtenção dos escravos na África, Tumbeiros: mortos

9 Martins. História 6. São Paulo, FTD, 1997. Edição reformulada. Livro distribuído pelo Programa Nacional do Livro Didático do Ministério da Educação e que é utilizado pelas professoras de forma incidental, conforme a necessidade por textos se apresenta. Os livros ficam guardados na sala de História e são distribuidos aos alunos durante as aulas e recolhidos ao final. 0 capítulo 16 corresponde 'as páginas 136 a 145 . 
e vivos viajavam juntos: condições das viagens nos tumbeiros, a comercialização nos mercados de escravos; Escravos: as mãos e os pés da sociedade brasileira, esta última sendo a parte onde o autor relata o cotidiano do trabalho e da vida de escravos do eito e domésticos, bem como as formas de resistência: fugas, assassinatos, o banzo, os suicídios e a formação de quilombos.

Essa apresentação é feita aqui para situar melhor o contexto em que está sendo realizado o trabalho de construção do conceito de relações sociais escravistas e oferece subsídios para analisar a afirmação de Chevallard de que o professor não faz a 'transposição didática' e sim trabalha na 'transposição didática'10.

Durante as aulas por mim observadas, os aspectos referentes aos conteúdos históricos stricto sensu foram abordados a partir de textos do livro didático onde a 'transposição' do saber a ensinar já havia sido iniciada. Elas montaram todo o trabalho para promover uma leitura e análise significativa dos textos do livro pelos alunos, mas o encaminhamento para explicar a opção pela escravidão na Idade Moderna, a opção pelo africano, por exemplo, era o do livro. 0 trato com o saber específico era bastante dominado pelo texto do livro, diferentemente do que acontecia quando trabalhavam com os procedimentos e as atitudes. Assim, por exemplo, ao iniciar o estudo sobre a escravidão, não foi realizada nenhuma problematização. A professora explicou que eles iriam fazer um trabalho “.... para aprender a fazer pesquisa. Não é ir copiando dos livros e da internet. É preciso aprender a escrever com as próprias palavias."

Ela ajudou-os a localizar o primeiro parágrafo. Pediu a um aluno para ler, o que foi feito com certa dificuldade. Ela leu em voz alta e perguntou se eles lembravam do que estudaram na $5^{\circ}$ série. Ela foi perguntando e encaminhando as respostas deles, de forma clara e minuciosa. Na terceira pergunta, "Por que a escravidão foi aos poucos terminando na Grécia e em Roma?", um aluno respondeu que foi porque o cristianismo pregava a igualdade entre os homens. A professora disse que não foi bem assim.... Ela explica: "Roma deixou de fazer conquistas e diminuiu o número de escravos. Com a diminuição do número de escravos, Roma entrou em crise. 0 império romano desapareceu."

\footnotetext{
${ }^{10}$ Utilizo o conceito de transposição didática considerando as observações feitas anteriormente neste texto e que implicam no entendimento de que este processo é uma mediação didática enão um simples deslocamento do campo acadêmico para o campo educacional.
} 
A explicação, um tanto reducionista, não foi objeto de maiores reflexões. Era visível a preocupação em situar a escravidão na Roma antiga para servir de referência para a comparação com a escravidão moderna.

Ela perguntou então se só houve escravidão na Antiguidade. Os alunos responderam que houve também no Brasil. Ela então solicitou aos alunos que lessem e escrevessem, com suas próprias palavras, e de formà resumida, a idéia central de cada parágrafo. Ao ensinar como se lê o parágrafo e como se "conversa" com o parágrafo, ela dramatizou a leitura e fez perguntas para ela mesma:

"Mas eu tenho que tirar a idéia principal ....Alguém tem uma idéia de como eu posso fazer isso? Quem me ajuda? Será que era uma boa começar pelo sujeito desse negócio aí? Sim .. Portugal e Espanha trouxeram escravos para trabalhar na agricultura e na mineração..... Qual é a razão, por que?Aluna responde: Porque o trabalho assalariado não era generalizado.... A professora comenta: Puxa, muito bem, vê como ela faloụ diíícil... Pode ser. . .não era comum....."

Ela escreve no quadro:

'Portugal e Espanha usaram o trabalho escravo na agricultura e na mineração porque 0 trabalho assalariado não era comum."

Depois de fazer duas frases resumo, ela propôs que eles começassem a trabalhar sozinhos, em grupo. Ela ia, de grupo em grupo, para atender 'as solicitações dos alunos, os elogiava e, num certo momento, sentou junto deles para resolver a situação em que dois alunos trabalhavam e dois não faziam nada.

0 trabalho de construção continuou, na aula seguinte, com a leitura de dois resumos por ela elaborados, onde eles puderam encontrar semelhanças e diferenças entre a escravidão antiga e no Brasil. Depois da leitura, eles encontraram uma linha de tempo onde deveriam pintar de azul o período da escravidão antiga e de vermelho, aquele referente à escravidão moderna.

${ }^{11}$ Trechos extraídos de registros feitos por mim durante a observação da aula da professora da turma 601, no dia 07/04/2001. Pode-se perceber nestes dois exemplos que a explicação construída ficou em um nível de generalização muito grande, gerando uma simplificação que pode levar a construção de idéias equivocadas sobre o tema em estudo. 
Seguiu-se a apresentação de duas imagens, uma mostrando o interior de um tumbeiro e outra um desenho retratando um mercado de escravos, extraído de um livro de Asterix. Eles deveriam identificar as imagens, numerandoas de acordo com uma legenda que dizia:

1) em Roma e Grécia antigas;

2) na América, sobretudo no Brasil.

Era uma atividade de reconhecimento das diferenças e identificação dos contextos.

Depois foram apresentados dois quadros comparativos onde os alunos deveriam escrever as atividades econômicas realizadas pelos escravos na Grécia e Roma Antigas e na América. No outro, eles deveriam escrever os nomes dos continentes onde se desenvolveu o escravidão e por último, era solicitada a elaboração de um texto onde eles apontariam e explicariam uma semelhança existente quando comparamos a escravidão antiga e o moderna.

Concluindo o trabalho, foi solicitado que eles, em duplas, "produzissem um diálogo entre dois escravos ou escravas. Um deles seria um escravo da Roma Antiga. 0 outro, um escravo brasileiro. Apesar de viverem em épocas diferentes, os dois, imaginariamente, se encontrariam num filme de ficção. Os alunos seriam os narradores da história. A conversa entre os dois deveria esclarecer algumas questões sobre diferenças e semelhanças entre essa forma de relação de trabalho - o escravismo."

A atividade teve como objetivo promover a oportunidade de elaboração textual própria que possibilitasse aos alunos expressar a sua apropriação dos conteúdos e que, an mesmo tempo, propiciasse o processo de acomodação na concepção piagetiana. Foi uma forma, também, de criar oportunidade para utilizaçã̃o dos novos conhecimentos de forma cotidiana, na criação de um diálogo imaginário o qual eles revelassem o domínio dos conceitos reformulados..

Apresentado de forma geral, acredito que fica muito claro, neste exemplo, como a construção realizada para o ensino se configura como característicamente escolar. A partir dos subsídios apresentados, e que resgatavam saberes ensinados no ano anterior, outros presentes no texto do livro didåtico e aqueles conhecidos de forma difusa pelos alunos sobre a escravidão no Brasil, os alunos identificaram características da escravidão na América e, através da comparação, as semelhanças e diferenças entre esta e na Antiguidade. 
É uma atividade pautada pela perspectiva construtivista onde são apresentados subsídios para que os alunos identifiquem características para formar o conceito. Não é um trabalho estruturado numa lógica dedutiva que apresenta o conceito e sua definição, conforme estabelecida pelo conhecimento científico, para depois analisar situações que ele ajuda a analisar e compreender. É uma construção elaborada, a partir de subsídios do saber acadêmico, que permite criar uma situação de aprendizagem na qual o aluno caracteriza a escravidão na antiguidade e na modernidade, identificando as diferenças e as semelhanças. Nesse trabalho, as professoras estão criando condições para que os alunos construam o conceito, que implica num certo nível de generalidade, mas que precisa dar conta das situações particulares, exigência intrínseca e expressa de forma própria no conhecimento histórico.

Como diz Prost(1996, p. 129) "os conceitos históricos são construídos por meio de uma série de generalizações sucessivas, e definidos pela enumeração de um certo número de características pertinentes, que dispensam a generalidade empírica, mas não a necessidade lógica." Ele se baseia em Koselleck(1990), que afirma: "Sob um conceito estão subsumidos a multiplicidade da experiência histórica e um conjunto de relações teóricas e práticas que, enquanto tal, não é dado nem é objeto de experiência a não ser por esse conceito" (1990, p. 109 apud PROST, 1996, p. 130).

Assim, o conceito de escravidão, ou de relações sociais escravistas, referese a um conjunto de relações estabelecidas entre os homens, em determinadas sociedades e tempos, que implicam em características como trabalho compulsório, transformação da pessoa em mercadoria, formas de apropriação e de dominação, regras para a legitimação do uso da violência pelo detentor do direito de propriedade sobre aquele que é escravizado, representações e discursos legitimadores da relação, e que se apresentam de forma própria nos diferentes contextos.

Essas características, que remetem a situações concretas, vividas, são definidas a partir das observações realizadas e são articuladas em função de concepções teóricas que orientam a análise. No caso das nossas professoras, por exemplo, estão orientadas para a análise econômica e social, e não por uma perspectiva cultural preocupada com as representações e visões de mundo. Essas concepções implicam, por sua vez, no processo de seleção dos conteúdos. 
Esssa questão, que envolve a discussão sobre o particular e o universal na História, é discutida por Prost (1996, p. 125-143). Ele lembra, inicialmente, e seguindo Koselleck(1990), que existem dois níveis de conceitos: "Toda historiografia se movimenta sobre dois níveis: ou bem ela analisa fatos que já foram expressos anteriormente, ou bem ela reconstroi os fatos que não foram expressos anteriormente na língua, mas com a ajuda de certos métodos e índices que de alguma forma já foram preparados. No primeiro caso, os conceitos herdados do passado servem como elementos heurísticos para conhecer a realidade passada. No segundo caso, a história se serve de categorias formadas e definidas ex post, e que não estão contidas nas fontes utilizadas" (KOSELLECK, 1990, p. 115 apud PROST, 1996, p. 126)

Embora com conteúdo concreto muito forte, as designações de época como 'servo', 'manso', 'oficial', 'quinto', 'lavras', possuem um certo nível de generalização que permite que sejam consideradas conceitos. Mas para o estudo das realidades passadas se faz necessário criar conceitos ou buscá-los em outras ciências, como, por exemplo, 'crise econômica', 'classe social', 'revolução' 'mercantilismo',etc processo este sempre ameaçado pelo risco do anacronismo. Nos dois casos, no entanto, o conceito resulta de um mesmo tipo de operação intelectual: a busca da generalização e/ou a síntese.

Os conceitos não são a coisa, são expressos por palavras que utilizamos para dizer a coisa, são as suas representações e que, portanto, traduzem significados compartilhados por alguns e, muitas vezes, de forma contraditória numa mesma sociedade. Mas, através deles, podemos vê-la e até pensá-la enquanto realidade.

A relação entre o conceito e a coisa representada é dialética: tanto 0 conceito permite pensar e compreender fenômenos que não são dados a ver de imediato, como o de 'exclusão social', para citar um exemplo atual, ou o de fascismo, tenentismo e muitos outros; ou permitem, com o aprofundamento da análise do seu significado, que possamos compreender aspectos antes ignorados (como é o caso da análise do conceito de mercadoria, por Marx).

0 conceito está relacionado a uma palavra, mas o está também ao mesmo tempo a mais de uma palavra; uma palavra se torna um conceito quando a plenitude de um contexto sociopolítico de significados e experiência dentro do qual e para o 
qual uma palavra é usada, pode ser condensado em uma palavra (KOSELLECK, 1985$, p. 84) $)^{12}$

Além disso, o trabalho do historiador implica a exigência de traduzir na linguagem de hoje o significado passado de palavras e, através delas, das realidades expressas. E mais ainda, o significado dos conceitos atuais deve ser redefinido se pretendemos traduzir o passado através deles. (PROST, 1996, p. 141-142)

Um outro aspecto relevante que precisa ser destacado é que, no âmbito da História, a construção conceitual implica numa dimensão temporal, pois os tempos de mudança nos conceitos não coincide com o tempo de mudanças da realidade. Como diz Koselleck, "As palavras que duram não constituem um índice suficiente da estabilidade das realidades" (KOSELLECK, 1990, p. 106 apud PROST, 1996, p. 141). Mas, também, as mudanças de terminologia não constituem um indício seguro de mudança na realidade (como podemos ver em várias situações do contexto brasileiro).

Os conceitos em História raramente são usados em sua forma absoluta. Geralmente eles são complementados por adjetivos que procuram explicitar a situação a que se referem. O sentido mais preciso é explicitado pelo adjetivo que ele recebe e o "jogo" comparativo implica também em buscar o adjetivo pertinente. Assim, em História, no lugar de se falar de revolução, falamos da revolução francesa, ou da industrial, ou da russa, ou da chinesa, ou da tecnológica, agrícola, etc., cada uma referindo-se a um contexto específico num tempo determinado. Assim, "a conceitualização em História opera uma organização do real histórico, mas uma organização relativa e sempre parcial, porque o real não se deixa jamais reduzir ao racional; ele comporta sempre uma parte de contingência, e as particularidades concretas tumultuam, necessariamente, a bela ordem dos conceitos" (PROST, 1996, p. 137).

${ }^{12}$ Koselleck, explicando o que é a história dos conceitos, destaca que uma palavra apresenta potencialidades de significado, um conceito une em si mesmo uma plenitude de significados. Portanto, um conceito pode ter claridade mas será sempre ambiguo. Nenhum conceito pode ser definido de forma que sintetize semioticamente um processo inteiro; somente o que não tem história pode ser definido. Por outro lado, embora os conceitos tenham relação com os contextos com os quais se relacionam, sua função e performance semântica não é unicamente derivada das circunstâncias sociais e políticas com as quais se relacionam. Um conceito não é apenas indicativo das funções que explica;ele é também um fator dentro delas (KOSELLECK, 1985, p. 84). 
Os conceitos em História implicam, portanto, em considerar sua relação com 0 real em perspectiva analógica e numa dimensão temporal sincrônica e/ ou diacrônica, o que possibilita o trabalho com a história dos conceitos (KOSELLECK, 1992).

Assm eles contêm, estruturalmente, potencialmente, elementos que abrem perspectivas para comparações, possibilitando o trabalho com as analogias, em uma "inteligibilidade comparativa" (PASSERON, 1991 apud PROST, 1996, p. 131), comparações estas que vão permitir avaliar se as características implícitas no conceito se encontram na coisa ou se é preciso reformular o conceito para dar conta de novas realidades criadas. De acordo com Passeron, nas ciências sociais a 'demarche' comparativa permite que se utilize a analogia controlada. "A validade da racionalidade científica repousa sobre a capacidade de exercer o controle da comparação" (LAUTIER, 1997, p. 75).

Essas considerações aqui apresentadas em relação ao uso dos conceitos no conhecimento histórico stricto sensu, estão baseadas, principalmente, no trabalho de Prost(1996), especialmente o capítulo 6- "Les concepts", que, por sua vez, utiliza como referenciais os trabalhos de Koselleck, Weber, Veyne e Marrou. Concluindo, convém lembrar Marrou quando este afirma que "não se deve esquecer que toda a comparação coxeia, que nunca existe em História, esse domínio do singular, paralelo perfeito nem recomeço absoluto. 0 uso de tais processos analógicos ou metafóricos requer precauções, habilidades..." (MARROU, 1974, p. 140).

Que relações podem ser estabelecidas entre essas considerações de ordem teórica e o trabalho de construção de conceitos na História - conhecimento escolar?

Acredito que temos, nas aulas observadas, um exemplo claro do diálogo realizado com o saber acadêmico, no processo de mediação didática(LOPES, 1999) e que dá origem ao conhecimento escolar. Temos a definição de um saber a ensinar (decidido no âmbito da noosfera) - as relações sociais escravistas. Este saber a ensinar vai sendo transformado em saber ensinado a partir de decisões tomadas pelos professores que escolhem alternativas que julgam mais apropriadas para o seu ensino. Aqui, a opção pelo construtivismo e pelo trabalho com a construção ds conceitos. São definidas situações de aprendizagem que levam os alunos a identificar características, diferenças e semelhanças, em diferentes tempos e espaços, incluindo o seu próprio tempo e espaço. Esse processo, que está 
referenciado ao processo de produção do conhecimento histórico, é realizado descontextualizado das questões específicas da pesquisa e de seus pesquisadores. É recontextualizado para atender aos objetivos educacionais de formação da cidadania daqueles alunos e por isso, são dessincretizados e programados de acordo com suas necessidades, interesses e características culturais (CHEVALLARD, 1991, p. 69-73). As referências aos pesquisadores e autores não são feitas nem é explicado o trabalho com as fontes. A preocupação com a pesquisa se concentra no ensino da atividade, como uma metodologia a ser apropriada pelos alunos. Como já foi comentado, o saber ensinado, a história escolar me pareceu muito subordinada 'as preocupações mais evidentes com a formação de atitudes e dos procedimentos de pesquisa. As referências feitas pelas professoras na entrevista são aos PCNs e ao livro didático.

A analogia, que é utilizada pelas professoras ao comparar a escravidão antiga e a moderna, torna-se um recurso extremamente rico e pertinente pois permite aos alunos avançar no processo de construção de conceitos dentro de uma lógica que é própria ao conhecimento histórico. Tratando-se de turmas de sexta série, os aspectos abordados são poucos, oferecendo elementos para uma formalização simples, mas que permite que eles reconheçam em situações vividas ou estudadas, a existência ou não de relações sociais escravistas. Sua utilizaçã̃o expressa o potencial identificado por Prost nos conceitos históricos, revelando-se uma forma coerente de abordagem do ponto de vista epistemológico.

Acredito que a opção por elas adotadas na atividade analisada aqui foi bem sucedida no trabalho em perspectiva analógica em História. Elas se preocuparam em fazer os alunos perceberem diferenças e semelhanças entre a escravidão antiga e a moderna e não em usar uma como idêntica à outra. A comparação com as relações sociais no presente, propiciada pelo trabalho de pesquisa sobre "Que país é este?'” (que, embora não fosse especificamente sobre as relações de trabalho permitia, indiretamente, sua caracterização) criava um contexto que também era trabalhado através da identificação de diferenças e semelhanças.

A definição do conceito a ser ensinado pressupõe a atribuição de um significado pelas professoras que servirá de referência para a criação de situações de aprendizagem, num processo que apresenta similaridade com aquele utlizado no trabalho com os tipo-ideais de Weber. Esses conceitos são referências que não determinam que a apropriação dos alunos será aquela esperada pelo 
professor. Essa construçã̃o é realizada num espaço onde existe liberdade para que as leituras e intervenções dos diferentes alunos possam se efetivare, inclusive, aprofundar as análises e ampliar os significados. É a troca entre os diferentes sujeitos históricos envolvidos na rede intertextual que possibilita a emergência do significado do conceito em estudo naquele momento.

A dimensão temporal foi trabalhada na perspectiva da localização temporal, e não da simples enunciação de datas, e como elemento estruturante do raciocínio histórico na medida em que articulou a dimensão diacrônica- os significados das relações escravistas em diferentes temporalidades - com a dimensão sincrônica, no caso, a concepção de relações escravistas na mente dos alunos, na atualidade.

Note-se também que elas utilizaram frequentemente a linha do tempo, criação didática do conhecimento escolar, de forma adequada como instrumento para auxiliar o aluno na localização. Um reparo que pode ser feito é quanto à escala utilizada que não respeitou as diferentes durações das épocas históricas.

Por último, um aspecto que merece ser analisado, é aquele referente à explicação histórica que foi utilizada nas aulas sobre escravidão. Como já dissemos, ela se baseou fundamentalmente no texto do livro didático que, certamente, foi escolhido pelas professoras porque contemplava de alguma forma suas exigências quanto ao conteúdo a ser ensinado.

0 exemplo escolhido refere-se ao estudo do texto do livro didático para entender por que ocorreu a volta do trabalho forçado na América, ou, em outras palavras, o por que da utilização de escravos na América. A atividade consistia em ler cada parágrafo e escrever a idéia principal. Curiosamente, a professora, ao auxiliar os alunos, organizados em grupos na sala de Hsitória, a fazer o trabalho, explorou muito mais os aspectos da leitura do que a problematização histórica.

A professora escreveu no quadro:

Portugal e Espanha usaram o trabalho escravo na agricultura e na mineração porque o trabalho assalariado não era comum.

Continuando, a professora conseguiu esta frase, que ela também escreveu no quadro: 
Para os portugueses e espanhóis terem altos lucros, gastando pouco, era necessário não pagar salários. Por isso escravizaram os negros africanos e os índios.

Analisando estas explicações, podemos perceber que elas simplificam demasiadamente um processo que envolveu: a experiência portuguesa com os escravos africanos, a possibilidade de utilização do indígena, a disponibilidade de terras, a pequena população de Portugal, a necessidade do trabalho compulsório que se colocava a partir deste contexto e que era próprio da época. A explicação pautou-se, no entanto, na afirmação de que o trabalho assalariado não era comum e que não poderiam pagar salários porque queriam ter altos lucros. Mas já é sabido que a obtenção dos escravos, principalmente os africanos, implicava em custos vultosos para a época quando de sua aquisição. Não pagar salários não significava automaticamente ter altos lucros. Lembremos outra vez que esta era a explicação constante do livro.

Mas por que esta opção foi tomada? A questão dos salários só pode ser considerada relativamente neste caso até porque, como o próprio texto afirma, ele não era comum. Esta ênfase pode ter sido uma opção do autor para escolher, entre os fatores que compõem esta explicação, aquele que é familiar ao aluno: 0 trabalho assalariado. A partir dele montou-se a explicação, o que implicou em uma distorção. ${ }^{13}$

Já o trabalho com o texto, o ensino de como se deve ler para extrair a idéia principal, foi primoroso, revelando uma habilidade no trato com 0 ensino da leitura e da escrita que são fundamentais para o ensino/ aprendizagem da História.

Neste caso, vemos um exemplo em que a aproximação com a realidade do aluno, no caso aspectos da atualidade, é feita de forma implícita gerando uma explicação que, embora avance em relação 'aquelas que afirmavam que os africanos estavam acostumados com a escravidão, precisaria e poderia ser burilada para melhor dar conta da problemática abordada, mesmo numa sexta série. O movimento realizado para tornar o assunto familiar ao aluno redundou numa simplificação, evidenciando um risco que ronda os processos de contextualização na "realidade dos alunos".

\footnotetext{
${ }^{13}$ Faço aqui uma inferência a partir da situação observada. Não faz parte desta pesquisa investigar concepções e pressupostos de autores de livros didáticos.
} 
Percebe-se aqui também uma subordinação da questão histórica face 'as exigências educativas, no caso, o desenvolvimento da leitura e da escrita. Um outro aspecto que merece ser destacado é quanto 'as recorrências do saber escolar entre as quais identificamos a utilização da periodização em idades que incluem a pre-história, e as idades antiga, média, moderna e contemporânea. Essa periodização tem sido, há muitos anos, objeto de severas críticas por parte dos historiadores, por implicar, entre outros motivos, numa forma de representação que, além de europocêntrica e linear, simplifica de forma radical a complexidade do processo histórico. Quando de sua apresentação no início do ano letivo, os professores têm o cuidado de discutir esses problemas com os alunos mas, até o fazem porque trabalham com essa periodização como referência. No trabalho dessas professoras, ela é utilizada para demarcar os períodos na linha do tempo. Esta periodização, que é um exemplo de criação do conhecimento escolar(França do século XIX,apud Furet), apesar de implicar numa simplificação e homogeneização de cunho europeizante, continua sendo utilizada pelos professores. Qual a sua funcionalidade do ponto de vista do ensino?É um recurso útil que precisa ser aprimorado ou é ainda utilizado porque os professores não dominam recursos alternativos que possam melhor dar conta das demandas que 0 trabalho com a noção de tempo impõe?.

Concluindo, considero que o trabalho desenvolvido apresentou qualidade uma vez que atendeu aos objetivos propostos do ponto de vista educativo e manteve um diálogo com o conhecimento historiográfico que respeitou suas características do ponto de vista epistemológico-como pode ser visto no trabalho com os conceitos. Do ponto de vista dos conteúdos abordados, merecem ser atualizados com base nas pesquisas sobre escravidão. Aspectos culturais não foram explorados mas cabe considerar o caráter introdutório, de fundamentação, das aulas observadas.

A dimensão educativa permeou todo o trabalho realizado ao possibilitar que os alunos tivessem contato com experiências históricas diferentes das suas, e também através da perspectiva crítica que orientava de forma incidental todo o estudo. Junte-se a isso a orientação sobre procedimentos de pesquisa escolar de forma autônoma e o trabalho de desenvolvimento da leitura e da escrita.

Outros exemplos poderiam ser citados, mas isto implicaria em alongar em demasia 0 texto. Aqueles que foram analisados permitem configurar a 
construção do saber escolar realizada na história ensinada pelas duas professoras, que revela sua originalidade face ao conhecimento acadêmico e qualidade na sua realização pois permitiu a construção de conhecimentos de uso cotidiano pelos alunos, conhecimentos estes informados pelas contribuições científicas, superando equívocos e preconceitos presentes no senso comum.

\section{Bibliografia}

APPLE, M. Ideologia e currículo. São Paulo, Brasiliense,1982.

BRASIL. Ministério da Educação. Secretaria de Ensino Fundamental. Parâmetros Curriculares Nacionais. História. Brasília, MEC/SEF/1998.

CAILLOT, M. "La theorie de la transposition didactique est-elle transposable?' In: $A u-$ delá des didactiques, le didactique. Debats autour des concepts federateurs. Paris, Claude Raisky et Michel Caillot Éditeurs, 1996.

CHERVEL, A. "História das disciplinas escolares: reflexões sobre um campo de pesquisa." in Teoria\&Educação no 2.Porto Alegre: Pannonica Editora, 1990. (177-229).

CHEVALLARD, Y. La transposición didáctica. Del saber sabio al saber enseñado. Buenos Aires: Aique Grupo Editor,s.d.

CHEVALLARD, Y. e JOSHUA, M-A.La transposition didactique. Du savoir savant au savoir enseigné. Suivie de Un exemple de la Transposition didactique. Postface.

DEVELAY, M. De l'Apprentissage à l'enseignement. Pour une épistémologie scolaire. Paris, ESF Éditeur, 1992.

DEVELAY, M. Savoirs scolaires et didactique des disciplines: une encyclopédie pour aujourd'hui. Paris,ESF Editeur,1995.

FORQUIN, Jean-Claude."Saberes escolares, imperativos didáticos e dinâmicas sociais" in Teoria\&Educação no 5 .Porto Alegre: Pannonica Editora, 1992. (28-49).

. Escola e Cultura. As bases sociais e epistemológicas do conhecimento escolar.Porto Alegre, Artes médicas,1993.

"Evoluções recentes do debate sobre a escola, a cultura e as desigualdades na França" IN: FRANCO, C. (org) Avaliação, ciclos e promoção na Educação. Porto Alegre, Artmed, 2001. 
FURET, F. "0 nascimento da História" in FURET,F. A oficina da História. Lisboa: Gradiva, s.d.

GAUTHIER, C. Por uma teoria da pedagogia.Pesquisas contemporâneas sobre o saber docente. Ijuí,(RS), Editora Unijuí, 1998.

GÓMEZ,A.P. " 0 pensamento prático do professor. A formação do professor como profissional reflexivo." IN: NÓVOA,A.(org.) Os professores e sua formação. Lisboa, Publicações Dom Quixote,1995.

GOODSON,I. "Tornando-se uma matéria acadêmica: padrões de explicação e evolução." in Teoria \& Educação nº 2.Porto Alegre: Pannonica Editora, 1990. (230-254).

. Currículo: teoria e história.2.ed.Petrópolis(RJ):Vozes, 1998.

KOSELLECK, R.(1)." Historia Magistra Vitae: The Dissolution of the Topos in the Perspective of a Modernized Historical Process" in KOSELLECK,R. Futures Past. On the Semantics of Historical Time. Cambridge (Mass.) and London, The MIT Press, 1985.( 21-38)

. Le futur passé, contribution à la semantique des temps historiques, Pars, EHESS,1990.

. "Uma história dos conceitos:problemas teóricos e práticos." In: Estudos Históricos. 10 Teoria e história. Rio de Janeiro, FGV.1992.

LAUTIER, N. Enseigner l'Histoire au Lycée. Formation des enseignants. Professeurs des lycées. Paris,Armand Colin, 1997.

LOPES, A.R.C. "Conhecimento escolar:processos de seleção cultural e mediação didática." In: Educação\&Realidade. 22(1):95 -112.jan-jun.1997.

. Conhecimento escolar: ciência e cotidiano. Rio de Janeiro, Ed. Uerj, 1999.

"Questões para um debate sobre o conhecimento escolar." In: Ensino de

História. Revista do Laboratório de Ensino de História da UFE. v.3, n. 3,out.1999.

MARTINAND, J. L. Connaitre et transfomer la matiére. Berne,Peter Lang,1986.

MARROU, H-I. Do conhecimento histórico. 3.ed. Lisboa, Editora Pedagógica Universitária, 1974.

MONIOT,H. Didactique de L'Histoire. Paris, Edition Nathan,1993.

MONTEIRO, Ana Maria F. da C. "Ensino de História: entre saberes e práticas". Tese de Doutorado. Departamento de Educação.PUCRIO. Rio de Janeiro, 2002. 
MOREIRA, A. E. B.e SILVA. T.T .(Org.).Currículo, cultura e sociedade. São Paulo:Cortez, 1994.

. "Currículo, utopia e pós-modernidade" IN: Moreira, A.F.B.(org.) Currrículo: questões atuais. Campinas: Papirus, 1997.

. Currículo: questões atuais. Campinas,Papirus,1997.

PASSERON, J.-Cl. Le raisonnement sociologique. L'Espace non popperien du raisonnement naturel. Paris,Nathan,1991.

PROST, A. Douze leçons sur l'histoire. Paris, Editions du Seuil,1996.

SANTOS, L. L. de C. P. "História das disciplinas escolares: perspectivas de análise." in Teoria\&Educação $n^{\circ}$ 2.Porto Alegre: Pannonica Editora, 1990. (21- 29).

SILVA, T. T. da. Documentos de identidade. Uma introdução às teorias do currículo. Belo Horizonte, Autêntica, 1999.

VERRET, M. Le temps des études. Lille: Atelier de reproduction de théses, 1975.

VEXNE, P. O inventário das diferenças. Lisboa, Gradiva, 1989.

. Comment on écrit l'histoire. Paris, Ed. du Seuil, 1971.

WEBER, M. Essais sur la théorie de la science. Paris,Plon,1965.

YouNG, M. Knowledge and Control. Londres:Collier-Macmillan,1971.

\section{History teaching: configurations of school knowledge}

ABSTRACT

The interest in History teaching has increased lately configuring a research field undergoing a great development in Brazil. In this way, the use of the concepts "school knowledge" (Forquin, Develay, Lopes), "school discipline" (Chervel, Goodson) and "didatic transposition" (Chevallard, Develay, Moniot), "didatic mediation"(Lopes) offer instigating perspectives to help understanding the characteristics of processes inherent in school culture, which specificity is then recognized and considered. The exclusive use of theoretical instruments pertinent to historiographic research to analyse knowledges and practices belonging to a 
culture with proper logic and dynamics has produced misunderstandings such as the identification of errors where there were only differences. The purpose of this article is to discuss some configurations proper to school knowledge, identified and analysed in the so called "curriculum in action" or, in other words, in History taught at schools, where the theoretical instruments of historiography is articulated with those belonging to the educational research field to approach and analyse constructions produced in school teaching, where instruction is imbricated with educational purposes.

Key-words: History teaching, school knowledge, historical school knowledge, didatic mediation, conceptual constructions, curriculum. 